\section{Spanning protection}

\section{Kenneth Mellanby}

The Environmentalist.

Editors David Hughes-Evans and

James L. Aldrich.

Elsevier Sequoia. 4/yr. SFr185, \$90.75.

THIS is an ambitious journal. The publishers claim that it will appeal to "all professionals concerned with education, training and communication in every area of environmental protection", and that it will bridge the gap between industrialists, government employees and conservationists.

The contents show a wide international coverage among authors and their subjects, yet most of the writers seem to be members of the professional international conservation elite. Also though it was entirely appropriate for the first number to contain a 10,000 word profile of $\mathrm{Dr} \mathrm{H}$. J. Coolidge, an American who has made a unique contribution to international conservation, it may not have been wise to dedicate a number in the second volume to Dr Coolidge, and to include a further

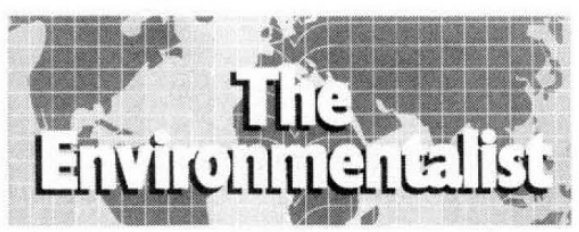

tribute to him, written by Dr Lee Talbot, Director General of the International Union for the Conservation of Nature. It was perhaps not surprising to find a profile of Dr Lee Talbot himself in the same volume.

Each number contains up to ten substantial articles. These are not entirely confined to the usual topics supporting the conservation line, for there is a 15,000 word defence of nuclear power. In general, however, articles deal with planning, wildlife problems, pollution, and training for service in the third world. The articles are factual and well written, but do not contain new information based on the writer's own research. Each number devotes some ten pages to News and Comments; informative notes on personalities, events like the vandalism of orchids in Britain, and jubilation over the better protection of the whale. These may make interesting reading, but I am doubtful whether a periodical appearing only four times a year should try to act as a newspaper, for much of this news is stale before it appears. I am afraid I cannot see this journal having the wide appeal hoped for by its producers.

Kenneth Mellanby was the first Director of Monks Wood Experimental Station set up by the British Nature Conservancy in 1961.

\section{Newborn eke-ology}

\section{R.W. Raiswell}

\section{Environmental Toxicology and}

Chemistry: An International Journal.

Editor-in-chief C.H. Ward.

Pergamon. 4/yr. £42.50, \$85.

Chemistry in Ecology.

Editor E.J. Perkins.

Gordon \& Breach. 4/yr. £161, \$242.

ECOLOGY, derived from the Greek word oikes, literally means house or habitation used in the sense of the immediate environment of man but in current usage it describes the science concerned with the interrelationships between organisms and their surroundings; the term being first coined by the German zoologist Ernst Haeckel in the 1860s. However, he could have derived the word from the AngloSaxon root which gives the verb to eke and accurately reflected the rapid increase in journals covering ecology and related fields.

So the addition of two more journals prompts one to question the laws of supply and demand, particularly in respect of the quality of contributions. However these fears appear unfounded, doubtless to the lament of librarians everywhere. Chemistry in Ecology (CE) shows some signs of a rather un-ecological caesarian, as opposed to natural, birth in that the first issue is mainly contributions from the editors' institution but subsequent issues evolve, from mostly camera-ready copy and an over-dramatic cover, to a higher quality, more uniform and formal style. At the price this seems the least one should expect in a journal of average size.

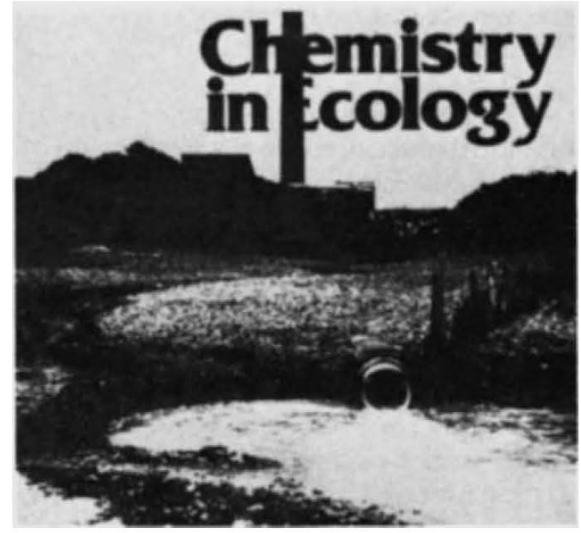

$\mathrm{CE}$ aims to bridge the gap between chemists and ecologists by covering the questions to which the other may usefully contribute. The papers attracted generally fulfill these objectives and their coverage extends over a range of physical, inorganic and organic chemical influences on organism activity. These contributions have been quickly produced, are of average size and reasonable quality. Review articles are not explicitly invited but there is a book review section. A thoughtful editorial review suggests a strong guiding presence and if, despite this, the journal is unsuccessful it will be warning to us all.

By contrast Environmental Toxicology and Chemistry (ETC) has altogether sounder antecedents, being sponsored by the Society of Environmental Toxicology and Chemistry and produced after a survey of involved professionals indicated a need for a journal representing the discipline. Although somewhat delayed in its inception, the journal has arrived in an established and tightly-produced form. It seeks to embrace three fields, Environmental Chemistry, Environmental Toxicology and Hazard Assessment which are, usually, represented in separate sections in the journal, each with its own editorial board.

It will be interesting to see if the editors can maintain a balance of quality, quickly produced articles in all three sections, as is the case in the early issues. ETC will include cricial reviews, research papers, short communications and discussion. The quality of production is good although diagram lettering is often over-reduced. The omens are good for ETC and it deserves success.

R.W. Raiswell is a Lecturer in the School of Environmental Sciences, University of East Anglia.

\section{Captive lives}

\section{Keith Hodges}

Zoo Biology.

Editor Terry L. Maple.

Alan R. Liss. 4/yr. $\$ 70$.

THE future survival of animals in captivity and in the wild depends upon a knowledge of the factors limiting reproductive output. Zoos now have a responsibility to increase this knowledge by acting not only as refuges for rare and endangered species but as establishments for research into animal management, breeding and fundamental zoology. The publication of zoo research therefore is important for conservation and basic science alike.

Zoo Biology is the first American scientific journal dedicated to this and, in principle, is a welcome addition to the limited existing outlets such as International Zoo Yearbook and Journal of Zoology. The journal is attractive in format and as well as full length research articles, includes brief communications, book reviews and editorials. The quality of some of the illustrations and plates, however, could be improved and the publication latency is difficult to assess at present. The annual UK subscription is modest although each of the four issues contains not more than 100 pages.

The editorial board is overwhelmingly North American, comprising about $\mathbf{4 0 \%}$ 